\section{What skulduggery?}

\section{Steve Blinkhorn}

The Mismeasure of Man. By Stephen J. Gould. Pp.352. ISBN 0-393-01489-4. (W.W. Norton: 1981.)\$14.95, £9.95.

WITH a glittering prose style and as honestly held a set of prejudices as you could hope to meet in a day's crusading, S.J. Gould presents his attempt at identifying the fatal flaw in the theory and measurement of intelligence. Of course everyone knows there must be a fatal flaw, but so far reports of its discovery have been consistently premature.

The theme of this particular book is that since science is embedded in society, one must expect to find the prejudices of the age presented by scientists as fact. Most authors, given such a theme, would be content to document and catalogue instances in support of the proposition. Gould, however, goes one better by writing a book which exemplifies its own thesis.

It is a masterpiece of propaganda, researched in the service of a point of view rather than written from a fund of knowledge. For the best propaganda requires not the suppression or distortion of facts but their careful selection, emphasis and juxtaposition. So, in a work which declares its concern to be with the notion of intelligence as a single measurable "thing" in the head, we find that two-thirds of the argument is given over to a careful reworking of early attempts to establish craniometric and anthropometric criteria of intelligence, and an admirably disturbing account of the Gadarene rush to press IQ tests into the service of social engineering in the USA in the first half of this century. As Gould rightly emphasizes, many of the uses to which tests were put made mockery of their original purpose.

Ottery
A fitter fits;
A cutter cuts;
And an aircraft spotter spots;
A baby-sitter
Baby-sits -
But an otter never ots.
Though sinners sin
And thinners thin
And paper-blotters blot;
I've never yet
Had letters let
Or seen an otter ot.
A batter bats
(Or scatters scats);
A potting shed's for potting:
But no one's found
A bounder bound
Or caught an otter otting.
From The Biology of Algae by Ralph Lewin. See
p.500 for details.

The final third of the book is the attempt proper to debunk the notion of general intelligence as arising specifically in the school of factor analysts starting with Spearman. But by this stage the reader has been presented with sufficient examples, sufficiently carefully examined, of racial and social prejudice in the work of scientists, of distorted data, fudged analysis and twisted interpretation as to the inexpert might establish a necessary connection. Add to that the soft target of Cyril Burt, some rather inaccurate observations on the role and effects of the $11+$ examination system in Britain and a remarkably detailed account of antique methods of factor analysis, and you have all the makings of a lively, plausible, opinionated and zesty potboiler.

But verbal fluency is no substitute for good arguments in the long run. The substantive discussion of the theory of intelligence stops at the stage it was in more than a quarter of a century ago. Consequently there is no account of attempts to characterize the psychological nature of general intelligence, no indication that multivariate methods have progressed beyond Thurstonian techniques, no discussion of the effects of ageing, of brain damage, of compensatory programmes, no account of modern behavioural genetics, of heritability studies other than Burt's, no hint of the current interest in cybernetic models or recent attempts by experimental cognitive psychologists to account for psychometric findings.

Gould even gives a perfectly straightforward account of what heritability would and would not mean in terms of the modifiability of intelligence, but fails to point out that such arch-hereditarians as Eysenck and Jensen have published essentially identical accounts. One is, presumably, meant to conclude that adherence to the notion that there is a measurable single dimension of intelligence necessarily involves the kind of radical nativism which was prevalent in times when genetic theory and statistical methods were in their infancy.

But this is a book with a double punchline. Or to put it another way, Gould performs the remarkable trick of pulling the rug from under his own feet whilst appearing to stand stock still. For not only does he propose a totally unobjectionable definition of intelligence ("the ability to face problems in an unprogrammed ... manner'), which, far from being novel, is a nice rewording of a definition proposed by Cattell in the context of a heavily factoranalytic theory and something of a commonplace amongst the intellectual heirs of Spearman, he even proposes essentially craniometric criteria of neoteny as a basis for the adaptability of Homo sapiens, and produces a photographic comparison of adult and infant chimpanzees with the remark that "if a picture's worth a thousand words . . .".

The truth of the matter is that Gould has nothing to say which is both accurate and at issue when it comes to substantive or methodological points. His "fatal flaw" (the purported dependence of the notion of general intelligence on details of factor analytic technique), the unsupported assertion that "disadvantaged" groups always perform worse on IQ tests, his strictures on the application of the notion of intelligence across species boundaries, his attempt to link the use of IQ tests in Britain with a rigid class structure, all have the routine flavour of Radio Moscow news broadcasts when there really is no crisis to shout about. You have to admire the skill in presentation, but what a waste of talent.

Steve Blinkhorn, a Senior Lecturer in Psychology at Hatfield Polytechnic, is currently working at the Neuropsychology Laboratory, Stanford University.

\section{Beyond selfish genes}

\section{Sydney Brenner}

The Extended Phenotype: The Gene as the Unit of Selection. By Richard Dawkins. Pp.307. ISBN 0-7167-1358-6. (W.H. Freeman: 1981.) £9.95, \$19.95.

THIS book, as Richard Dawkins states in his first chapter, "is a work of unabashed advocacy". It does not put forward new theories or new facts, but it advocates a special way of looking at living things and the worlds they inhabit.

This point of view, called the extended phenotype, is a development of the ideas discussed in his earlier book The Selfish Gene where, it may be remembered, Dawkins aimed to dispose of the organism as the unit of natural selection. He argues that this unit is the gene, or, rather, entities which are called germ line replicators, of which genes are the most important examples. Adaptations are for the benefit of these elements and not for anything else. Of course, it is admitted that these replicators are useless by themselves (you can buy them in bottles as chemicals called DNA) because selection judges them only by their effects in other entities, called vehicles, which the replicators inhabit. Biologists have given one such discrete vehicle, the organism, a special role as a unit of structure and function and it is this hold that Dawkins wants to break. He claims that replicators have extended phenotypic effects, reaching out beyond the boundaries of the organisms where they happen to be lodged into the world outside, even entering other organisms. He wants to dissolve organisms:

We see through them to the replicating fragments of DNA within, and we see the wider world as an arena in which these genetic fragments play out their tournaments of manipulative skill. Genes manipulate the world 
and shape it to assist their replication.

\section{Later he speaks of the}

image of a turmoil of selfish replicators, battling for their own survival at the expense of their alleles, reaching unimpeded through individual body walls as though these walls were transparent, interacting with the world

The extended phenotype is certainly a big idea and it is pressed hard in dramatic language. But does it help to view genes as active agents, manipulating, reaching, battling? I think it only obscures the essential feature of living organisms which distinguishes them from all other complex natural systems and which gives them the capacity for evolution. It is that they are propagated by passing on not themselves but an internal representation of themselves in their genes. Exactly how this correspondence is implemented is what most biologists study; knowing it must be important if only for understanding what genetic variation can generate. To a molecular biologist, all the stuff around the genes is anything but transparent; it is hard to see the replicators through the fog of complicated machinery, nor do they reach out so easily as Dawkins wants them to.

Dawkins still has to come grips with this central issue. In a section on the poverty of preformationism he would like to make a distinction between the central dogma of molecular genetics and that of embryology. The former states that information in protein cannot be translated back to nucleic acids: the equivalent in development is that "bodily form and behaviour may not be translated back into proteins". I think we agree that the former is a fact, not a question of principle, but why does Dawkins want to make the latter a principle and not simply an equivalent fact? After all, in the end we shall need to explain the effects of genes on bodily form and behaviour in terms of proteins; that is the only way for us to reach into organisms and for genes to reach out into the world. The molecular, cellular and organismic grammar connecting genes and phenotypic effects is the heart of the matter and the only way to explain how random changes in DNA can produce all the sense we observe in the living world.

Organisms exist. Even Dawkins realizes that he needs to bring back individual organisms. His extreme position has forced him into calling the organism a "phenomenon that needs explanation", and he of fers only a summary sketch on the last page. He says:

It has paid replicators to behave gregariously. The phenotypic power by which they ensure their survival is in principle extended and unbounded. In practice the organism has arisen as a bounded local concentration, a shared knot of replicator power.

Sounds terrific, but what does it mean?

Sydney Brenner is a member of the scientific staff of the Medical Research Council at the Laboratory of Molecular Biology, Cambridge.

\section{The whys (and wherefores) of behaviour}

\section{Aubrey Manning}

Ethology: Its Nature and Relations with Other Sciences. By Robert A. Hinde. Pp.320. Hbk ISBN 0-19-520370-4; pbk ISBN 0-00-636237-0. (Oxford University Press/Fontana: 1982.) Hbk £9.20, \$15.95; pbk $£ 2.95$.

ETHOLOGISTS are no longer a distinctive breed; indeed the days when one could recognize them from their background and framework of theory were quite short. Large parts of the original theory built up from Lorenz's dichotomizing between the "innate" and the "acquired" in behaviour, and the energy model of drives, have been abandoned. What has endured is an approach to the animal in its natura environment which is highly productive and infectious. When Lorenz and Tinbergen built up their schools following the Second World War, ethology came as an invigorating breeze across the arid fields of so much of the white rat experimental psychology of the day. Its influence has persisted and spread widely into other areas of behavioural science.

Robert Hinde's book sets out to give an account of modern ethology and to examine this influence. He succeeds well and this is both a useful and a stimulating book. I particularly liked the brief historical introduction to each section. Since modern ethology only goes back about 30 years and Hinde himself has been a highly influential figure over most of this period, we get a direct picture of an emerging discipline as it interacts with others already established.

The plan of Hinde's opening section on "core ethology"' derives from Tinbergen's classic paper of 1963, "On the Aims and Methods of Ethology". This was a landmark in the history of the subject and it represented a clear break of approach between Lorenz, who then had just published a reaffirmation of his own unchanging views on innate behaviour, and Tinbergen, who saw far more clearly that the old dichotomies (nature or nurture etc.) would no longer do. Tinbergen enunciated four types of question in relation to behaviour: those concerning its immediate causation, its development, its function (in the sense of survival value) and its evolution. Hinde has chapters covering each of these topics - he calls them ethology's four "whys". In fact they form a very good introduction which both covers some of the classic ethological studies and is also right up to date.

There is no introduction to this new Masterguides series itself and I am uncertain what audience they seek. Other titles include Religion, Law and Social Anthropology, so I imagine that "the educated layman" is once more in mind. Hinde is certainly not writing at an elementary level, nor can he bear to let first-stage simplifications stand. Readers without some behavioural background will find parts rather heavy going and there are one or two over-complex diagrams. References to the literature abound on almost every page, and no doubt or inadequacy of the evidence is left unexposed. Just these latter qualities, of course, will commend the book to the serious student. Its main body is Hinde's assessment of the influence which ethology has had upon related fields in biology and the human social sciences. They cover a huge range, from ecology to psychiatry, and are consistently illuminating. Hinde's coverage of the literature is extraordinary and he provides good linking passages so that an overall picture of the interrelationships of these fields is built up.

Within the biological sciences Hinde includes comparative and experimental psychology whose interactions with ethology were often stormy. The personalities, as well as the scientific achievements, of people such as Schneirla, Lehrman and Beach were of great importance in determining the course of the interchanges and Hinde gives enough of the history to make us fully aware that science is a human activity. The influence of ethology in the human social sciences has also met with opposition. The contributions it can provide are, first, the comparative method, revealing the human species as one amongst many which may share certain attributes, and secondly a secure descriptive method for the early stages of behavioural analysis. Neither of these appealed to those social scientists who emphasized the uniqueness of the human species or who concentrated solely on the cognitive and perceptual aspects of human behaviour.

Such extreme positions are rarer now. The study of non-verbal communication, of the attachment between mothers and infants and of the effects of maternal separation have all very obviously gained from ethological techniques and concepts. Hinde himself has made valuable contributions in these areas and his sharp and revealing focus is clearest in these sections of the book. The critical edge is somewhat blunted when dealing with the biological approach to anthropology where some of the wilder shores of sociobiology are dwelt upon rather too gently, but all is brought back into balance in his concluding remarks.

This book will be of great value to students and teachers in other fields who want to broaden their ethological horizons. It also provides a liberal education in these other fields for more biologically based ethologists.

Aubrey Manning is Professor of Natura History in the University of Edinburgh. 